\title{
The role of language in the online evaluation of hospitality service encounters: an empirical study
}

Article

Accepted Version

Creative Commons: Attribution-Noncommercial-No Derivative Works 4.0

Mariani, M. M., Borghi, M. ORCID: https://orcid.org/00000002-4150-1595 and Kazakov, S. (2019) The role of language in the online evaluation of hospitality service encounters: an empirical study. International Journal of Hospitality Management, 78. pp. 50-58. ISSN 1873-4693 doi: https://doi.org/10.1016/j.ijhm.2018.11.012 Available at https://centaur.reading.ac.uk/81129/

It is advisable to refer to the publisher's version if you intend to cite from the work. See Guidance on citing.

To link to this article DOI: http://dx.doi.org/10.1016/j.ijhm.2018.11.012

Publisher: Elsevier

All outputs in CentAUR are protected by Intellectual Property Rights law, including copyright law. Copyright and IPR is retained by the creators or other copyright holders. Terms and conditions for use of this material are defined in the End User Agreement. 


\section{CentAUR}

Central Archive at the University of Reading

Reading's research outputs online 


\title{
The role of language in the online evaluation of hospitality service encounters: An empirical study
}

\begin{abstract}
In an increasingly global travel market, hospitality services encounters involve growing interactions between providers and customers often belonging to different nationalities and cultures and speaking different languages. Extant hospitality management literature has explored the influence of language on service evaluations mostly in offline settings. This study innovatively captures the effect of the language used in online hotel reviews on online consumer ratings in two distinctively different destinations located in culturally different countries: Italy and Russia. Based on almost half a million Booking.com online reviews written by hotel guests in Moscow and Rome, we illuminate if and to what extent domestic vs. foreign language use affects online customer satisfaction. We find that the use of domestic language exerts a positive impact on online ratings in both countries. Implications for hospitality practitioners and managers, developers and managers of online review platforms, and customers of hotel services are discussed.
\end{abstract}

Key words: language, hospitality service encounters, online ratings, eWOM, empirical study. 


\section{Introduction}

International tourist arrivals have recorded a dramatic growth over the last six decades reaching the historical record of 1.3 billion in 2017, despite cyclical economic and political crises have interrupted some of the tourism flows (UNWTO, 2018). A high number of factors have contributed to the expansion of the global travel, tourism and hospitality markets. Besides economic factors such as the growth of GDP and income allocated to travel, demographic trends, increasing protection of travellers' rights, shifts in consumption patterns, undeniably the development of communication and transportation technologies has played a major role in the aforementioned expansion (UNWTO, 2017).

On the one hand, the improvements in transportation technologies have made it easier and more affordable for travellers to reach an increasing number of destinations. On the other hand, the evolution of information and communication technologies and more generally of digital technologies has allowed travellers to meet with people with distinctively different cultural backgrounds both online and offline. As such, technological development has significantly contributed to globalization processes.

The hospitality industry is one of the services industries that has been mostly affected by globalization: indeed hospitality firms interact daily with customers from different cultural backgrounds (see Mattila, 1999; Wang et al., 2015). To date, inter-cultural and cross-cultural hospitality service encounters and their evaluation have been analysed by means of field experiments and traditional surveys gathering a limited number of services customers (see Mattila, 1999, 2000; Tse \& Ho, 2009; Wang et al., 2008; Wang et al., 2015).

However, scarce attention has been paid to the impact that cultural factors may bear in the online evaluation of hotel services, with the exception of a few recent studies (see Gao et al., 2018; Liu et al., 2017; Schuckert et al., 2015) that have emphasized to what extent cultural differences can affect hotel consumer behaviours in online settings. This is rather surprising as today hospitality services are assessed by leveraging online review platforms such as Tripadvisor and Online Travel Agencies (OTAs) such as Booking.com, and online ratings are becoming paramount for both consumers' and companies' decision making (Cantallops \& Salvi, 2014).

As cultural differences still play a major role in today's globalized world and in the hospitality sector, it is of paramount importance to investigate how cultural differences such as the use of different languages (domestic vs. international) can affect hotel online hotel ratings. The analysis conducted in this paper is distinctive for the following reasons: 1) it captures to what extent the use of domestic vs. foreign language affects online ratings after hospitality service encounters in different destinations/countries; 2) it leverages an extensive dataset of almost half a million online 
reviews representing the overall population of reviews endowed with text written by hotel guests in two culturally different destinations/countries (attracting different mixes of leisure/business tourists) over a period of 24 months; 3) it encompasses among the research settings also the Russian hospitality sector, that is often neglected in hospitality management studies.

The rest of the paper unfolds in a number of sections and is organized as follows. Section 2 introduces the theoretical background and builds on the theoretical antecedents to present the major research hypothesis. The third section displays the empirical setting and research methodology. Section 4 describes the research findings. The fifth section discusses the implications. The last section elucidates the conclusions, the major limitations and a promising research agenda.

\section{Theoretical background and hypotheses formulation}

\subsection{Service encounters, hospitality service encounters and impacts on service evaluation}

Services research has traditionally recognized the centrality of consumers' involvement and participation in the service production (Bitner et al., 1997; Grönroos, 1978; Shostack, 1977). Marketing research introducing and discussing the co-creation paradigm in services management has further highlighted the role of the consumer as a value co-creator in a services setting (see Vargo and Lusch, 2004).

Services have been therefore conceptualized as encounters between service providers (namely contact personnel/employees) and customers/consumers (Grönroos, 1984; Lovelock, 1983; Zeithaml et al., 1996) whereby a service encounter is "a period of time during which a customer directly interacts with a service" (Shostack, 1985, p. 243). Effective service encounters have been found to generate high levels of customer satisfaction (Zeithaml et al., 1990), positive experience (Arnould \& Price, 1993), pleasure (Russell et al., 1989), retention and repurchase behaviours (Hennig-Thurau, 2004) and loyalty (Mattila, 2001).

However, to be effective, service encounters should build upon a number of factors that pertain to the service provider, the customer and the interaction between them. As far as service providers are concerned, an effective service encounter depends on: i) how well employees are able to follow a service process blueprint (Shostack, 1984), ii) the extent to which service providers can close the four service quality gaps of service design and standards, listening, service performance and communication (Zeithaml et al., 1990); iii) the capability of providers of transforming customers into business partners for value creation (Vargo \& Lusch, 2004); iv) the ability of interpreting performance measures related to customers (Sainaghi et al., 2013). 
As far as service customers are concerned, an effective service encounter depends on customers and their demographics (Kulik \& Holbrook, 2000), actions and knowledge of the service script and roles (Solomon et al., 1985), and voluntary and non-voluntary behaviours (Zeithaml et al., 2006) that ultimately influence the consumers' level of participation. Cultural factors such as the cultural background of customers have received a limited attention so far (de Mooij and Hofstede, 2011).

As far as the interaction between service providers and service customers is concerned, in services value is co-created by the customer during the consumption as clearly emphasized by the service-dominant (S-D) paradigm (Vargo \& Lusch, 2004). According to the S-D paradigm, customers and firms collaborate to create value. Co-creation implies effective interaction and communication between consumers and service providers: this could be problematic in crosscultural environments where the cultural background of the service providers might differ significantly from the cultures espoused by consumers (de Mooij \& Hofstede, 2011) and the language used (spoken and written) might affect the service interaction itself (Holmqvist \& Grönroos, 2012).

In hospitality management research, services encounters are at the heart of the industry (Chapman \& Lovell, 2006) and have been investigated adopting a variety of perspectives. The effectiveness of hotel service encounters is crucial as it is conducive to high levels of satisfaction (Pizam \& Ellis, 1999), customers' evaluations (Mattila, 2000), customer retention (Yung \& Chan, 2002), repurchase behaviours (Kandampully et al., 2001; Yung \& Chan, 2002) and loyalty (Mattila, 2001).

That said, effective hotel service encounters depend on a number of factors pertaining to hotel service providers, customers, and the interactions between hotel service providers and customers.

As far as hotel service providers are concerned, an effective hotel service encounter depends on: i) the behaviour of the employees (Cook et al., 2002) also in response to customer misbehaviour (Daunt \& Harris, 2014); ii) the training, proficiency and skills of employees (Chapman \& Lovell, 2006); iii) intercultural sensitivity of employees (Sizoo et al., 2003); iv) the servicescape shaped by providers (Chen et al, 2017); v) the way providers transform customers into partners (Shaw et al., 2011); vi) employees' emotions (Rafaeli \& Sutton, 1987).

However, an effective hotel service encounter also depends on: i) customers' demographics (Shoemaker and Lewis, 1999); ii) customers' actions and knowledge of the service script (Chen et al., 2017); iii) self-efficacy (Chen et al., 2015); iv) purchase importance (Chen et al., 2015); v) customers' involvement (Mattila, 2000, 2001); vi) roles and behaviours (Chen et al., 2017) that ultimately influence the consumers' level of information, attitude, and behavioural participation 
(Chen et al., 2017). Last but not least, the S-D logic is particularly relevant to explain how value is created in the hospitality sector as hospitality service encounters are co-created by the guest/customer and the employee/provider, and the participation of the customers in value creation is critical to shape the service experience (Chen et al., 2017; Shaw et al., 2011).

According to recent literature in hospitality management research, it appears that the best service provider/customer relationship in service delivery can be labeled as "mutual understanding" (Chen et al., 2017) and experimental studies demonstrate that intercultural communication plays a pivotal though neglected role in enabling mutual understanding in hospitality service encounters (Wang et al., 2015). To our knowledge, while in the mainstream marketing management and consumer behaviour literature, cultural factors have been taken into account (de Mooij \& Hofstede, 2011; Winsted, 1997), in hospitality services marketing research the role of cultural factors has been relatively peripheral in consumer behaviour studies until 2015 (except for Mattila, 1999, 2000, 2001; Sparks \& Callan, 1992; Sparks, 1994), with an upsurge of interest over the last 4 years (Wang et al., 2015, Gao et al., 2018).

Also language, being part of culture, has been largely neglected so far, with a very few exceptions (Schuckert et al., 2015; Liu et al., 2017; Wang et al., 2015) and certainly represents an area with a great research potential (Holmqvist \& Grönroos, 2012).

In the following subsections, we build on services management and marketing studies embedding intercultural and language differences to develop a research hypothesis relevant to the hospitality services. The uniqueness of this study lies in the examination of how the online reviewing language differences affect online ratings after hospitality service encounters in distinctively different destinations located in two culturally different countries: Italy and Russia.

\subsection{Cultural and language differences and consumers' evaluation of hospitality service encounters}

Cross-cultural and inter-cultural studies in hospitality service encounters have started appearing at the end of the nineties, typically in the form of field experiments, aiming at comparing and contrasting attitudes, behaviours, expectations, evaluations and satisfaction levels of hotel guests from two to five different countries or geographical regions, and often comparing Western vs. Eastern consumers (see Mattila, 1999, 2000, 2001; McCleary et al., 1998; Mok \& Armstrong, 1998; Reisigner \& Turner, 1999).

For instance, McCleary et al. (1998) scrutinize the importance of 56 hotel attributes for business tourists from the USA and Korea when choosing a hotel. Their study highlights that both Korean and American guests look after cleanliness, security, comfortable mattresses and pillows, 
friendly staff. However, while Americans put emphasis on the availability of non-smoking rooms, and hotel reputation, Korean business guests consider location, laundry and business services of paramount importance. Mattila (1999) finds that there are statistically significant differences between Western and Asian hotel guests in their evaluation of the service encounter and overall service quality. Focusing on leisure vs. business travellers, the author reveals the similarity of customers' evaluations of the service encounter and overall service quality of business travellers across the two regions. However, Asian leisure travellers are found to give a lower evaluation of the service encounter (as well as of overall service quality) than their Western counterparts.

Interestingly enough, several of these seminal studies on inter- and cross-cultural service encounters explain the findings mostly by means of theoretical frameworks and theories developed in the 1980s (Hall, 1984; Hofstede,1980). However, the role of language and language use in service marketing research has been to a certain extent neglected until the beginning of this decade (Holmqvist \& Grönroos, 2012) as most of extant research has focused on indirect communication such as advertising, branding, written messages (see Luna \& Peracchio, 2002; Puntoni et al., 2009).

Paradoxically, those contexts such as service settings, where language seems to play a paramount role, have received the least scholarly attention (Holmqvist \& Grönroos, 2012) despite the fact that "the interactive and intangible nature of services means that language, language skills, and language difficulties will increasingly influence how consumers perceive, execute, and evaluate their service interactions with companies." (Holmqvist \& Grönroos, 2012: p.429).

Building on communication and interaction research in services (see Luna \& Peracchio, 2002; Puntoni et al., 2009; Sparks \& McColl-Kennedy, 2001) and on sociolinguistic research (Clément et al., 2002; Giles et al., 1987; Gopinath \& Glassmann, 2008; Aune \& Toshiyuki, 1993), Holmqvist \& Grönroos (2012) put forward 11 theoretical propositions related specifically to language use before, during and after services encounters. In their tenth proposition, they deal with the service encounters aftermath and posit that one of the unanswered research questions to address is "to what extent does language influence word of mouth?". To our knowledge, this question has not been addressed thoroughly so far in mainstream service marketing research, and, more specifically, the related question in contemporary online settings "to what extent does language influence electronic word of mouth?" remains virtually even not formulated in services settings. Holmqvist and Grönroos (2012) suggest that after a service encounter, consumers' evaluations of effective and positive communication should encourage them to spread positive WOM about the service provider (Harrison-Walker, 2011).

As far as the role of communication and language in hospitality service encounters, pioneering contributions have focused on the description of several aspects of communication in 
hospitality services (Sparks \& Callan, 1992; Sparks, 1994). For instance, Sparks (1994) finds that hotel reservationists adopting a convergent style of communication were rated higher, with female customers giving generally higher ratings. She also concludes that service providers should be better trained in communicating their knowledge of tourism products. Sparks and Callan (1992) show that the quality of interpersonal and intercultural relationships between hotel customers and providers are enhanced by a convergent style of communication.

Drawing on literature from communications and social psychology, Wang et al. (2015) study intercultural service encounters (ICSEs) in a foreign context (i.e., customers engaging in a service encounter when traveling abroad) rather than a domestic context (i.e., customers engaging in ICSEs in their country of residence). They find that consumers respond to communication accommodation strategies with increased felt pleasure, arousal, and dominance (as well as relational and symbolic value) that ultimately positively affect encounter satisfaction.

\subsection{Language differences and consumers' evaluation of hospitality service encounters in online settings}

In their reference work on the role of language in services, Holmqvist and Grönroos (2012) emphasize that Internet deserves a significant attention as it "facilitates contact between consumers and service providers from language groups around the world" (ibidem, p. 439), therefore "contributing to a marked increase in international and intercultural communication." (ibidem, p. 439).

The introduction and consolidation of digital technologies and digital communication generate significant opportunities for services companies but also increased challenges in intercultural communication that need timely research and an in-depth understanding (Holmqvist and Grönroos, 2012; 2017). This is even more relevant in the hospitality sector where online reviews are becoming increasingly relevant as a source of information for both companies and consumers (Hennig-Thurau et al., 2004; Dellarocas et al., 2007). In their seminal definition, Hennig-Thurau et al. (2004) have termed online reviews as electronic word-of-mouth (eWOM) whereby eWOM is "any positive or negative statement made by potential, actual, or former customers about a product or company, which is made available to a multitude of people and institutions via the Internet” (Hennig-Thurau et al., 2004, p. 39).

The hospitality sector has been deeply affected by eWOM (Litvin et al., 2008) and a substantial amount of research has been carried out around review-generating factors and impacts of eWOM (Cantallops \& Salvi, 2014). 
Within the extant body of eWOM literature, a very few studies have tried to assess the role played by language in affecting online consumer behavior. The first pioneering study in hospitality management embedding language in the study of online consumer behaviour has been an analysis of English vs. non-English speaking customers in hotels in Hong-Kong (Schuckert et al. 2015). The study finds that there are differences in ratings between non-English speaking and English speaking guests, with the former ones preferring low-class hotels. Moreover, it shows that online ratings satisfaction differences are bigger in lower class hotels or in hotels with more non-English speaking guests. The aforementioned study considers English-speaking customers as a proxy of foreign customers. However, this is not always the case and might differ across destinations: for instance, in Western European destinations English might be just one of the several languages used by foreign visitors and guests.

Moreover, we embrace the idea that while most of the studies in the wide social sciences and socio-linguistic research have focused on English, any generalization based on English data should be corroborated and refined by considering data from other language communities (e.g., Cenni \& Goethals, 2017; Smakman, 2015). For instance, Liu et al. (2017) focus on 412,784 Tripadvisor online reviews of Chinese hotels and find that foreign tourists of 8 different language groups assess hotels differently online based on the evaluations they give of hotel attributes such as rooms, location, cleanliness, service and value.

The present study looks at online service evaluations after intercultural service encounters, controlling for both domestic and international tourists. Therefore, it does not simply control by a specific language such as English (Schuckert et al. 2015), but clearly differentiates between domestic language vs. foreign languages to address the question put forward by Holmqvist \& Grönroos (2012): "to what extent does language influence word of mouth?" in an online setting. Moreover, unlike Schuckert et al. (2015), our unit of analysis are the individual reviews. Our study also differs from the analysis carried out by Schuckert et al. (2015) and Liu et al. (2017) as we focus on hotels located in two distinctively different countries to generalize our findings and look at language related issues outside of the Chinese context.

Overall, both theory and empirical observation show that language plays a crucial role in service encounters as it provides a common basis for communication between the service providers and the consumers (Holmqvist and Grönroos, 2012; Holmqvist et al., 2017) and experiential research in hospitality suggests that speaking the same language can avoid misunderstandings and miscommunication (Manzur \& Jogaratnam, 2007) and that language accommodations seem to affect positively customers' felt pleasure, control and thus satisfaction (Wang et al., 2015). Based on the received theory, we therefore hypothesize that if the hospitality service provider and the 
consumer use the domestic language of the focal destination, this would decrease the likelihood of miscommunications, misunderstndings and communication gaps and break-downs, thus ultimately leading to positive eWOM after the service encounter. Accordingly, we hypothesize what follows:

Hypothesis: The domestic language is positively related to online review ratings, so that hotel guests using the domestic language in their online reviews tend to give higher ratings, regardless of the type of destination (prevalently leisure vs. prevalently business), its degree of internationalization, and the country where the hotels are located.

There are several features and aspects that make this study distinctive compared to previous research: (a) it covers multiple destinations located in different countries with different service cultures; (b) it covers both prevalently leisure and prevalently business destinations; (c) it covers both prevalently domestic and prevalently international destinations; (d) it is not only confined to understand the impact of English vs. non English language groups on online ratings but looks at the use of domestic vs. foreign language in each of the diverse destinations analyzed; (e) it constitutes one of the first attempts to generalize the study of the relationship between the language used for reviewing purposes and online ratings across distinctively different destinations; (f) it builds on online reviews that are certified and therefore reflect the judgments of real guests that actually stayed in a hotel, written after the hospitality encounter; $(\mathrm{g})$ it provides novel insights on the type of strategies that online review platforms should develop when dealing with multilingual communities.

\section{Empirical setting and research methodology}

\subsection{Empirical setting: the choice and relevance of the destinations under analysis}

We situate our study in two distinctively different destinations belonging to two distinctly different countries and cultures somehow underrepresented in language related hospitality management studies: namely Moscow in Russia and Rome in Italy. The two countries feature among the Top 10 countries in terms of international tourist arrivals (UNWTO, 2018) and the two cities are the leading destination cities in their respective countries in terms of bed nights with respectively 17.6 million bed nights in Moscow (Cushman \& Wakefield, 2017) and 26.9 million bed nights in Rome in 2016 (European Cities Marketing, 2017). However, they differ significantly across the following dimensions:

a) in terms of supply, the Russian hotel industry was mostly developed only after the collapse of the former Soviet Union and until 1990 it was mostly dominated by state-owned hotels offering basic services for domestic and small number of foreign tourists. Higher-end hotels 
emerged only after the start of a free market economy in the early 90s (Balaeva et al., 2012). On the other hand, the Italian hospitality industry has a more consolidated tradition whereby small and medium hotels have been playing a paramount role since the 50s and higher end hotels have a long and consolidated presence (Battilani \& Fauri, 2009). Currently the Muscovite hospitality industry is dominated by 2- and 3-star hotels while the Rome-based hospitality industry records a prevalence of 3- and 4-star hotels (this is also evident from the data understanding carried out on the overall population of Booking.com online reviews retrieved for the two studied years);

b) in terms of consumer demand patterns, Rome is characterized as a prominently leisure destination, while Moscow receives an equal amount of business and leisure tourists. This is quite clear based on a data understanding on the overall population of Booking.com online reviews retrieved for the two cities over the period February 2015 - February 2017: hotel guests that travelled to Rome for leisure purposes were $83.4 \%$ compared to just $52.0 \%$ travelling for leisure to Moscow;

c) with respect to consumer demand, Rome is a more international destination than Moscow because out of 26.9 million bed nights recorded in 2016, 19.4 million (72.1\%) pertained to international tourists (European Cities Marketing, 2017), whereas for Moscow out of 17.6 million bed nights, only 5.5 million $(31.3 \%)$ were related to foreign guests (Cushman \& Wakefield, 2017). This data pattern is in line with the overall population of Booking.com online reviews retrieved for the two studied cities over the period February 2015 - February 2017: international guests reserving a hotel stay and reviewing a hotel in Rome were 68.5\% while international guests reserving a hotel stay and reviewing a hotel in Moscow were $24.8 \%$;

d) last, in terms of demand there is a further difference between Moscow and Rome. Moscow is characterized by a significant presence of domestic travellers and foreign tourists that are originally from the former Soviet countries where Russian is either the official language (see Belarus, Kyrgyzstan and Kazakhstan) or is considered as a lingua franca (Azerbaijan, Estonia, Georgia, Latvia, Lithuania, Moldova, Tajikistan, Turkmenistan and Uzbekistan). On the contrary, Rome is characterized by a significant presence of international tourists and, when tourists are originally from abroad, they do not necessarily speak Italian.

From the aforementioned data it is clear that the destinations considered are relatively different both in terms of supply and in terms of demand, and they were chosen for this research so that they could display a sufficient variety in terms of features and characteristics of their supply and demand. 
Moreover, our study allows covering a relevant research gap that is evident in both hospitality management and socio-linguistic literature: the over-emphasis on English language and English language text analysis (Cenni \& Goethals, 2017; Smakman, 2015). Clearly, results and generalization that are based on English data should be confirmed, checked and refined by taking into account data from other language groups and communities (Cenni \& Goethals, 2017): this is certainly a value added of this research. This issue is becoming an increasingly relevant issue in today's digital platform dominated travel industry whereby online review platforms have to develop multilingual features and policies (see Hale, 2016; Lenihan, 2011; Goethals, 2016).

\subsection{Data}

In the next three subsections, we describe data collection, variable operationalization and data analysis.

\subsubsection{Data collection}

Data was collected from the Online Travel Agency Booking.com. Online travel reviews were scraped from the Online Travel Agency (OTA) Booking.com. The platform was chosen not only because it is extremely popular (it covers 1,742,801 properties across 130,447 destinations in 227 countries and territories worldwide and 1,5 million room nights are reserved on it every day (https://www.booking.com/content/about.en-gb.html), but also because it hosts the highest share of certified online reviews worldwide (Mariani \& Borghi, 2018). Furthermore, it is often mentioned together with Expedia - as a source to carry out multi-platform analyses on eWOM (Gao et al., 2018; Xiang et al., 2017).

One of the researchers developed a crawler in the Python programming language to collect online reviews of Muscovite hotels over the period February 2015 to February 2017. The crawler simulated an Internet user's access to the hotels available for the destination and her browsing for all the details related to the property.

Thus, we created two relational datasets: one including company level data and the other including reviews level data. At the company level, we scraped information including the name of the hotel, its street address, the overall rating, the hotel class and whether or not the hotel belongs to a chain. At the individual online review level, we collected all the data related to each individual review encompassing the timestamp, declared name of the reviewer, her/his country of origin/residence, the language in which the review was written, the number of reviews s/he wrote, the length of the hotel stay, the purpose of the trip (business or leisure), the travel companions (whether the travelers was travelling solo, in a couple, in group, with their family, etc.). We 
therefore collected all of the aforementioned data over a 2 years window (February 2015 - February 2017). They cover the overall population of hotels listed on Bookig.com in Moscow and Rome: 670 with 657 of them displaying at least one review in Moscow (for a total of 387,812 reviews) and 857 with 851 of them displaying at least one review in Rome (for a total of 603,987 reviews). However, as in this study we focus on the effect of domestic vs. non-domestic language, we retained only those reviews where text was available (and therefore language could be determined) totaling 164,757 reviews for Moscow and 333,481 for Rome (for an overall total of 498,238 reviews). Overall, reviewers are from 92 countries in Moscow and from 101 countries in Rome.

\subsubsection{Variable operationalization}

Our dependent variable is the overall Booking.com rating of the hotel which varies from 2.5 to 10.0. Our focal independent variable is the language used to write the review that can be either domestic or non-domestic.

In addition, we included control variables such as the reviewer's experience in online reviewing (i.e., the number of reviews written by a specific reviewer) (RE), the purpose of the trip (leisure or business), the type of travelling group (solo, couple, etc.) as well as hotel class and chain. We also included an interaction effect (Domestic Interaction) to detect any possible moderating effects if the focal traveller is international and uses the domestic language of the destination where they are accommodated for reviewing purposes.

The description of the variables is illustrated in the Table 1 below:

Table 1 - Variables description

\begin{tabular}{|l|l|}
\hline \multicolumn{1}{|c|}{ Variable } & \multicolumn{1}{|c|}{ Description } \\
\hline Domestic Language & $\begin{array}{l}\text { It is the language used to write the review. It is a dummy } \\
\text { variable whose value is } 1 \text { if the language used to write the } \\
\text { review is the domestic language of the country/destination } \\
\text { where the hotel is located (i.e., Russian for Moscow or } \\
\text { Italian for Rome) }\end{array}$ \\
\hline Domestic Interaction & $\begin{array}{l}\text { It is a dummy variable whose value is 1 if the focal traveller } \\
\text { is international and uses the domestic language of the } \\
\text { destination where they are accommodated for reviewing } \\
\text { purposes (e.g., it equals } 1 \text { if a UK traveller reviews in } \\
\text { Russian language after staying at a hotel located in Russia). }\end{array}$ \\
\hline
\end{tabular}




\begin{tabular}{|l|l|}
\hline Rating & Online rating posted by a reviewer \\
\hline Reviewer Experience (RE) & $\begin{array}{l}\text { Value that represents the number of reviews written in the } \\
\text { past by the reviewer (i.e., the reviewer' online experience in } \\
\text { writing online reviews) }\end{array}$ \\
\hline $\begin{array}{l}\text { Observed Average Rating } \\
\text { (Obs_Avg_Rat) }\end{array}$ & $\begin{array}{l}\text { Hotels' review average rating as observed by the reviewing } \\
\text { guest }\end{array}$ \\
\hline Length of Stay (LoS) & Number of nights spent in the hotel by the reviewer \\
\hline
\end{tabular}

The descriptive statistics for the relevant variables in the two destinations are summarized in Tables 2.a and 2.b:

Table 2.a - Descriptive statistics for the Moscow sample

\begin{tabular}{lcccccc}
\hline & Mean & SD & \% Yes & Blau Index & Min & Max \\
\hline Domestic language & & & $78.9 \%$ & 0.33 & 0 & 1 \\
Domestic Interaction & & & $4.8 \%$ & 0.09 & 0 & 1 \\
Rating & 8.02 & 1.79 & & & 2.5 & 10.0 \\
RE & 9.66 & 14.68 & & & 1.0 & 312.0 \\
Log (RE) & 1.52 & 1.21 & & & 0.0 & 5.74 \\
Obs_Avg_Rat & 8.10 & 0.70 & & & 2.5 & 10.0 \\
LoS & 2.30 & 1.96 & & & 1.0 & 36.0 \\
\hline
\end{tabular}

Table 2.b - Descriptive statistics for the Rome sample

\begin{tabular}{lllllll}
\hline & Mean & SD & \%Yes & Blau Index & Min & Max \\
\hline Domestic language & & & $23.1 \%$ & 0.35 & 0 & 1 \\
Domestic Interaction & & & $0.7 \%$ & 0.01 & 0 & 1 \\
Rating & 8.06 & 1.70 & & & 2.5 & 10.0 \\
RE & 8.13 & 11.85 & & & 1.0 & 312.0 \\
Log (RE) & 1.45 & 1.12 & & & 0.0 & 5.74 \\
Obs_Avg_Rat & 8.08 & 0.69 & & & 2.5 & 10.0 \\
LoS & 2.85 & 1.61 & & & 1.0 & 28.0 \\
\hline
\end{tabular}

All of the variables display levels of skewness and kurtosis compatible with normal distributions given the sample size (as confirmed by the Jarque-Bera test and other nonparametric kernel density estimators), apart from the Reviewers' experience that has been therefore log-transformed. Interestingly the Blau Index calculated on both the subsamples of reviews written in the domestic language by foreign guests (equalling 0.09 for Moscow and 0.01 for Rome), signals a high level of 
intra-sample homogeneity and therefore implicitly supports the idea that the two destinations are different also with respect to the share of international guests speaking the domestic language.

\subsubsection{Data analysis}

Our main hypothesis was validated using multivariate ordinary least squares (OLS) regressions. OLS regressions are suitable when variables display multivariate normality, like in the case analysed. Our dependent variable, namely the Rating of a review (Rating) was regressed against the independent variables: domestic language, reviewer's experience (RE) in writing review, observed average rating (Obs_Avg_Rat), the interaction between domestic language and foreign country of origin. We also considered control variables including travel type (weather business or leisure), hotel class, hotel chain, as well as type of travelling group (solo, family with children, group, etc.).

\section{Analysis and findings}

The results of the analyses are illustrated in Table 3:

Table 3. Effect of language on online ratings

\begin{tabular}{lcccc}
\hline \multicolumn{1}{c}{ Independent Variable } & $\begin{array}{c}\text { Model 1 } \\
\text { (Moscow) } \\
\text { Coefficient }\end{array}$ & $\begin{array}{c}\text { Std } \\
\text { Error }\end{array}$ & $\begin{array}{c}\text { Model 2 } \\
\text { (Rome) } \\
\text { Coefficient }\end{array}$ & $\begin{array}{c}\text { Std } \\
\text { Error }\end{array}$ \\
\hline Domestic language & $0.186 * * * *$ & 0.01 & $0.074 * * * *$ & 0.007 \\
Domestic Interaction & $0.082 * * * *$ & 0.019 & -0.043 & 0.033 \\
Observed Avg Rating & $1.013 * * * *$ & 0.006 & $1.028 * * * *$ & 0.004 \\
Log (RE) & $-0.015 * * * *$ & 0.003 & $-0.015 *$ & 0.002 \\
Travel Type (Business) & $-0.327 * * * *$ & 0.01 & $-0.339 * * * *$ & 0.01 \\
Comp_Family & $0.128 * * * *$ & 0.013 & $0.008 *$ & 0.007 \\
Comp_Group & $0.164 * * * *$ & 0.015 & $0.110 * * * *$ & 0.008 \\
Comp_People with friends & $0.280 * * * *$ & 0.066 & $0.137 * * *$ & 0.046 \\
Solo_Traveller & $0.069 * * * *$ & 0.011 & $0.054 * * * *$ & 0.009 \\
Constant & $-0.295 * * * *$ & 0.053 & $-0.242 * * * *$ & 0.043 \\
Company Controls & & & & \\
\multicolumn{1}{c}{ Star rating $\quad$ Yhain } & YES & & YES & \\
$\mathrm{R}^{2}$ & 0.1779 & & YES & \\
Adjusted R ${ }^{2}$ & 0.1778 & & 0.1863 & \\
N & 164,757 & & 333,481 & \\
No. Hotels & 651 & & 851 & \\
\hline
\end{tabular}

Notes: ${ }^{*} \mathrm{p}<0.10 ; * * \mathrm{p}<0.05 ; * * * \mathrm{p}<0.01 ; * * * * \mathrm{p}<0.001$

Table 3 shows that the coefficient for the use (and knowledge) of the providers' language by the hotel guests appear to exert a significantly positive effect $(\mathrm{p}<0.001)$ on online review ratings in both the destinations analyzed. Therefore, our hypothesis is supported. This finding seems to indicate 
that the use of a common language constitutes a sound basis for effective communication between hotel service providers and customers (Holmqvist \& Grönroos, 2012), preventing from misunderstandings and communication breakdowns (Holmqvist et al., 2017; Manzur \& Jogaratnam, 2007). More importantly, language used to write reviews appears to positively influence eWOM in general thus contributing to a partial answer to the research question developed by Holmqvist and Grönroos (2012) on the relationship between language and WOM. More specifically, we show not only that language can affect the online customer ratings but also that domestic language regardless of the destination, type of destination (leisure or business) and country where the destination is located - affects positively online ratings.

Overall, the analysis of the focal independent variable suggests that in the different contexts under analysis it is the language used after (and presumably also during) the hotel service encounter that makes a difference for online ratings and thus for online customer satisfaction. Interestingly the finding is robust across the two destinations analyzed and seems to be valid regardless of the type of destination (business vs. leisure), the destination's share of international visitors, and the country where the hotel is located.

When we study the interaction effect of the focal independent variable and the presence of foreign tourists thus focusing on the subsample of foreign tourists that also speak the domestic language, our results differ slightly among the two destinations: in Moscow the presence of foreign tourists speaking Russian reinforces significantly $(\mathrm{p}<0.001)$ the positive effect of domestic language on online hotel ratings while in Rome the presence of foreign tourists speaking Italian does not moderate significantly the positive effect of domestic language on online hotel ratings. Therefore, also the relative share of foreign tourists speaking the domestic language of the destination visited does not modify the hypothesized positive relationship between domestic language and online hotel ratings.

As far as the reviewer-level control variables are concerned, reviewer's experience in online reviewing is negative and significant $(\mathrm{p}<0.001)$ in Moscow and in Rome $(\mathrm{p}<0.10)$. As the experience in online reviewing is to a certain extent related also to the experience in travelling, this finding seems to show that experience has a negative impact on reviewer's online ratings.

Reviewers travelling for business tend to give low ratings (the coefficient is negative and $\mathrm{p}<0.001$ ) and those travelling in company (with family, with friends or in groups) tend to give high ratings as the coefficients are significantly positive.

As far as the review-level control variables are concerned, the effect of the observed average rating is positive and significant $(\mathrm{p}<0.001)$. This finding is consistent with research proving that 
reviewers' ratings are affected by social dynamics (Gao et al., 2017; Ma et al., 2013). Finally, we have controlled our results for the hotel related variables such as chain and hotel class.

\section{Implications}

Based on a large dataset including almost half a million hotel reviews covering the most visited destination city in Russia (i.e., Moscow) and Italy (i.e., Rome), this study has captured if and to what extent the use of domestic language by consumers affects consumers' online rating behaviors. More specifically, we have examined the effect of language used for reviewing purposes on online consumer behaviors after the hospitality service encounters.

Two key findings emerge from the analysis. First, the use (and knowledge) of hotel services providers' language by hotel guests impacts in a significantly positive way online review ratings. This finding appears in line with the most recent services marketing research emphasizing that language plays a crucial role before, during and after services encounters (Holmqvist \& Grönroos, 2012; Holmqvist et al., 2017) and suggests that after hospitality services encounters it generates positive eWOM. Secondly, the reviewers' experience in online reviewing affects significantly the online ratings the reason being that experience in writing reviews is a good proxy of experience in travelling and therefore it is compatible with previous results showing that experience travelling exerts a negative impact on online ratings (Gao et al., 2018).

Overall, our findings provide a comprehensive appreciation of how cultural differences across countries - measured in terms of language gap between hotel service providers and consumers - can impact the online ratings behavior of online customers.

\subsection{Theoretical contributions}

This study contributes to the hospitality and tourism management literature in multiple ways. First, to the best of our knowledge, this is the first research addressing how the language discrepancy between hotel service providers and customers affects online customer behavior after hospitality service encounters. Accordingly, this study not only addresses a relevant unanswered research question within services marketing research (Holmqvist \& Grönroos, 2012) but is also innovatively enriches our understanding of the role of language in online consumer behaviors within hospitality services contexts, thus enriching extant hospitality management literature in online settings focusing on basic segmentations by language (e.g., Liu et al., 2017; Schuckert et al., 2015).

Second, the findings of the study demonstrate comprehensively that the language used (domestic vs. non-domestic) makes a difference in online consumer behaviors after intercultural 
hospitality service encounters. This complements research conducted recently on the use of intercultural communication accommodation in hospitality service encounters (Wang et al., 2015) even though more research is needed to understand if the reviewing language is also the language that was presumably used during the hospitality service encounter.

Last, this study contributes to the marketing and consumer behavior literature by assessing the impact of online reviewers' personal behavioral patterns and experience (i.e., experience in online reviewing) and language discrepancy between hotel services providers and consumers on online consumer behaviors by leveraging a comparative study covering multiple destinations. The findings hold across different destinations regardless of the type of destination (prevalently leisure vs. prevalently business), the share of domestic tourists received by hotels located in the destination, and the country where the hotels are located.

\subsection{Practical implications}

A number of practical implications stem from this study, including implications for hotel practitioners and managers, software developers and web administrators of online review platforms, and (online) customers of hotel services.

As domestic language positively influences the online review ratings in both the observed research settings, hotel managers and practitioners in both Moscow and Rome should pay attention to language as a key factor in their marketing strategies and tactics as it affects online customer satisfaction. Especially in Rome, since the minority of hotel guests use the domestic language, hotel management should be properly equipped to operate in a multi-lingual environment, regardless of the size and location of the hotel and whether the hotel is part or not of a chain. Hotel managers should use language as a key segmentation variable as this might be conducive to highly effective hospitality service encounters. Therefore they could implement different marketing and communication strategies and tactics to accommodate different language preferences. More specifically this could entail: developing an online presence (for instance through the hotel website) in a multi-lingual fashion, recruiting experienced multi-lingual staff and recording what language the guest has used during the reservation or upon arrival during the check-in to arrange for shifts of the hotel employees who can speak the indicated language. Hotel managers might tailor their communication before, during and after a hospitality service encounter based on the specific preferred language of their customers. More specifically, recording the preferred language of a guest into the company database might generate instantaneously knowledge about the customer

allowing the hotel to minimize communication gaps (Holmqvist \& Gronroos, 2012) and 
misunderstandings with the guests during their stay. The sooner the managers get to know the preferred language of the guest, the sooner they might instruct contact personnel.

In the Muscovite setting, hotel managers should gain an awareness that Russian speaking guests constitute a mass segment, while non-Russian speaking guests represent a niche segment. Therefore, hotels might tailor their communication strategies and tactics differently based on language and their searched positioning. For instance, for small and medium sized independent hotels located in less attractive areas of Moscow, it could be reasonable to rationalize costs for multi-lingual materials and staff. Certainly a different positioning choice might bring small boutique hotels located in the center or close to the Red Square to focus only on the niche market of non-Russian speaking guests visiting Moscow for leisure. Big hotels (whether or not part of hotel chains) instead should certainly differentiate their communication strategies and follow a more multifaceted approach to facilitate guest satisfaction, but keeping in mind that huge investments in differentiating their communication strategies might not necessarily create the value expected. Given that the country of residence of the guest can be typically identified through the reservation, hotel managers could provide directives and arrange for shifts of reception personnel to make sure that guests from non-Russian speaking countries might be welcomed by personnel able at least to speak English.

In both the settings, when a reservation is made online, it is possible for the hotel managers to track the country of residence of the upcoming guest, but not necessarily to know in advance the guest preferred language, unless the customer writes for a special enquiry through the reservation platform or by email. This might pose issues if a hotel is in shortage of multi-lingual personnel. Within both destinations, hotel managers could increasingly juxtapose traditional survey-based methods of evaluating service quality such as SERVQUAL (Parasuraman, et al., 1988) and SERVPERF (Cronin \& Taylor, 1992) questionnaires to Net Promoter Scores (Reichheld, 2003) and other recent techniques leveraging high volumes of data generated by online review platforms. Accordingly, it would be advisable for them to triangulate the assessment of hotel service quality from traditional surveys relying on small data with the evaluation of hotel service quality from analytics relying on big data ( $\mathrm{Li}$ et al., 2018) generated by online review sites.

Software developers and web administrators who operate OTAs and hospitality related web resources with built-in online review platforms will also benefit from the findings of this study because they increasingly deal with multilingual user generated content and search requests in many languages (Cenni \& Goethals, 2017). Online users want to browse and read information about a hospitality product in their preferred language, typically their mother tongue (Sun, 2001). Online 
travel platforms already invest heavily in multilingual solutions to meet the aforementioned need (Goethals, 2016) but probably they should increase their investments in the awareness that multilingual capabilities are currently taken for granted as a default feature. Hotel booking portals that will offer the best multilingual support will be able to reduce users' bounce rates, increase unique user session time, improve click-through rates, and ultimately enhance conversions and reservations. A few practical implications are derived for software developers and web administrators of online review platforms. First, in relation to usability, software developers and platform managers should make sure that language could be among the first criteria provided to users to view, read, browse and filter the hotel reviews online. As modern software can detect the location of the user based on the IP address, the highest amount of information should be made available to online customers in the main language spoken in the location they access the Internet from. While this has become a standard for Internet, many countries unite territories where different languages are spoken along with an official country language (for instance, there are 174 languages spoken in Russia alone). Certainly web site management could implement more advanced multilingual support for their online services if they plan to develop a global marketing strategy. Deeper localization and adaptation of the web services with an introduction of additional languages spoken within the same country may lead to increased online sales. Secondly, there is an obvious benefit when online reviews are written in the user's language and the same language is used in the platform interface. Such advantage is offered by both Tripadvisor and Booking.com that have enhanced their webpages to ensure that users accessing the website from a specific country can read the reviews written in their language right away. Third, increasingly platforms should make sure to develop functionalities allowing users from the same language to view each other reviews as this has been found to increase review usefulness (Liu \& Park, 2015). Fourth, platforms should increasingly encourage communication between different language groups by offering automatic translations of the hotel review text (Cenni \& Goethals, 2017) such as those provided by Tripadvisor. Relatedly, several Internet browsers (e.g. Google Chrome) automatically suggest translations when they detect the default language used by the device user. While the quality of automated translation is gradually improving thanks to advanced machine learning algorithms, still there is much to be done. Once website developers will have improved the translation function, they will be capable to promote closer interaction between domestic and foreign reviewers, as well as visitors speaking different languages, thus reducing information asymmetry and contributing to a more accurate and nuanced picture of the hospitality service being evaluated. Fifth, there is a possibility that frequent travelers access the platform from a country different from their resident country. In this case, tracking the IP address would not be enough for the platform to segment 
consumers, but additional mechanisms should be developed to ensure that the user could see first the review in her/his own language by default. One of such mechanisms could be a user-responsive user interface that can adapt to the default language of the device operating system or the preferred language saved in the browser memory.

Regarding the implications for hotel customers, the facilitation of interaction between users of the same language group(s) provided by the dominant online review platform Tripadvisor and the OTA Booking.com might be relevant for customers, as they tend to have more confidence in experienced reviewers with whom they find some degree of commonality and closeness (Vásquez, 2014) and that seem to share similar perceived cultural in-group identities (Giles et al., 2013). Second, a search filtering option based on nationality/country of origin may be an improvement opportunity as there is an assumption that consumers from a certain country of origin presumably will use its main official language. Booking.com currently offers this feature when users browse hotel online reviews but advancement could be possible in this area. Third, the increasing improvements in multilingual web design and technology will certainly help consumers belonging to different language group(s) to gain insights from online reviews shared by domestic tourists that might be more knowledgeable about the hotel (and destination). This might translate into availability to the customer of better information about the hotel service (and its attributes) prior to the reservation, that could be conducive to the formation of realistic expectations.

\section{Conclusions and limitations}

Our study contributes to the recent yet increasing research stream on cultural factors affecting eWOM in the hospitality and tourism sector and more specifically the literature related to the impact of language on eWOM (Schuckert et al., 2015), and offers insights on the role of language in online ratings and online rating behaviors.

First, by leveraging a large sample of almost half a million customer reviews related to hotels located in Moscow (Russia) and Rome (Italy), we find a positive correlation between the domestic language group members' reviews (i.e., the group of reviewers using the same language as the hospitality service providers) and the online hotel ratings. These findings address the research question of the impact of language on service evaluation and the impact of language on WOM after hospitality service encounters (Holqvist \& Grönroos, 2012; Holmqvist et al., 2017) with an extension to online settings. Secondly, the study further enriches and extends the findings of a recent study looking specifically at language in online settings (Schuckert et al., 2015). Accordingly, we are able to generalize findings related to the effect of consumers' used language on 
hotel service evaluation by leveraging on the big data extracted from online reviews ( $\mathrm{Li}$ et al., 2018). The findings of the study demonstrate comprehensively that the language used makes a difference in online consumer behavior after services encounters and this holds across different destinations regardless of the type of destination (prevalently leisure vs. prevalently business), the share of domestic tourists received by hotels located in the destination, and the country where the hotels are located. Last, this study contributes to the marketing and consumer behavior literature by assessing conjointly the impact of online reviewers' personal behavioral patterns and experience (experience in online reviewing) and language discrepancy between hotel services providers and consumers on online consumer behaviors.

While the analysis provides a rich set of implications for hospitality practitioners and managers, developers of online travel review platforms, and customers of hotel services, it is not without limitations. First, additional reviewer-level variables (such as age and gender) might be included in the model as controls or moderators to understand to what extent they can affect the impact of language discrepancy between hotel service providers and consumers on online ratings.

Second, it might be interesting to understand if and to what extent the use of domestic vs. non domestic language interacts with the style (use of literal vs. figurative language) that has been found to affect consumer attitudes and purchasing intentions (Wu et al., 2017) and might potentially influence also online consumer behaviour. Last, it would be interesting to check our findings and compare them across different online review platforms to generate further insights on online review behavior and better understand if strategies facilitating communication and reading across different language groups (multi-lingual strategies) are more, less or equally effective than strategies based on the use of translation mechanisms. 


\section{REFERENCES}

Arnould, E. J., \& Price, L. L. (1993). River magic: Extraordinary experience and the extended service encounter. Journal of Consumer Research, 20(1), 24-45.

Aune, R. K., \& Kikuchi, T. (1993). Effects of language intensity similarity on perceptions of credibility relational attributions, and persuasion. Journal of Language and Social Psychology, 12(3), 224-238.

Balaeva, O., Burnatseva, E., Predvoditeleva, M., Sheresheva, M., \& Tretyak, O. (2012). Network strategies of hospitality companies in emerging and transitory economies: Evidence from Russia. In Service science research, strategy and innovation: Dynamic knowledge management methods (pp. 519-546). IGI Global.

Battilani, P., \& Fauri, F. (2009). The rise of a service-based economy and its transformation: seaside tourism and the case of Rimini. Journal of Tourism History, 1(1), 27-48.

Bitner, M.J, Faranda, W. T., Hubbert, A. R., \& Zeithaml, V. A. (1997). Customer contributions and roles in service delivery. International journal of service industry management, 8(3), 193 205.

Browning, V. (2008). An exploratory study into deviant behaviour in the service encounter: how and why front-line employees engage in deviant behaviour, Journal of Management \& Organization, 14(4), 451-71.

Cantallops, A., \& Salvi, F. (2014) New consumer behavior: a review of research on eWOM and hotels. International Journal of Hospitality Management, 36, 41-51.

Cenni, I., \& Goethals, P. (2017). Negative hotel reviews on TripAdvisor: A cross-linguistic analysis. Discourse, Context \& Media, 16, 22-30.

Chapman, J. A., \& Lovell, G. (2006). The competency model of hospitality service: why it doesn't deliver. International Journal of Contemporary Hospitality Management, 18(1), 78-88.

Chen, S. C., Raab, C., \& Tanford, S. (2017). Segmenting customers by participation: An innovative path to service excellence. International Journal of Contemporary Hospitality Management, 29(5), 1468-1485.

Chen, R.X.Y., Cheung, C., \& Law, R. (2012). A review of the literature on culture in hotel management research: What is the future? International Journal of Hospitality Management, 31, 52-65.

Clément, R., Baker, S. C., \& MacIntyre, P. D. (2003). Willingness to communicate in a second language: The effects of context norms, and vitality. Journal of language and social psychology, 22(2), 190-209.

Cook, L. S., Bowen, D. E., Chase, R. B., Dasu, S., Stewart, D. M., \& Tansik, D. A. (2002). Human issues in service design. Journal of Operations Management, 20(2), 159-174.

Cronin, J. J., \& Taylor, S. A. (1992). Measuring Service Quality: A Re-examination and Extension. Journal of Marketing, 56(3), 55-68.

Cushman \& Wakefield OOO (2017). Moscow hotel market analysis. October 2017. www.cwrussia.ru/documents/.../0/...Moscow.../61a59bcb-de2d-4ee6-a6fc-497bcb8082fc/ (accessed 18.06.2018).

Daunt, K.L. \& Harris, L.C. (2014). Linking employee and customer misbehaviour: The moderating role of past misdemeanours, Journal of Marketing Management, 30(3-4), 221-244.

de Mooij, M., \& Hofstede, G. (2011). Cross-Cultural Consumer Behavior: A Review of Research Findings. Journal of International Consumer Marketing, 23, 181-192.

Dellarocas, C., Zhang, X., \& Awad, N. F. (2007). Exploring the value of online product reviews in forecasting sales: The case of motion pictures. Journal of Interactive Marketing, 21, 23-45.

Ernst \& Young. (2018). International Hotel Brands in Russia 2018. http://www.ey.com/Publication/vwLUAssets/EY-international-hotel-brands-in-russia2018/\$File/EY-international-hotel-brands-in-russia-2018.pdf.

European Cities Marketing. (2017). ECM benhmarking report 16/17. 13th Edition. Dijon: ECM. 
Filieri, R., \& McLeay, F. (2014). E-Wom and accommodation. An Analysis of the Factors That Influence Travelers' Adoption of Information from Online Reviews. Journal of Travel Research, 53(1), $44-57$.

Gao, B., Li, X., Liu, S., \& Fang, D. (2018). How power distance affects online hotel ratings: The positive moderating roles of hotel chain and reviewers' travel experience. Tourism Management, 65, 176-186.

Gao, B., Hu, N., \& Bose, I. (2017). Follow the herd or be myself? An analysis of Authors' contribution consistency in behavior of reviewers and helpfulness of their reviews. Decision Support Systems, 95, 1-11.

Giles, H., Ota, H., \& Foley, M. (2013). Tourism: An intergroup communication model with Russian inflections. Russian Journal of Communication, 5(3), 229-243.

Goethals, P. (2016). Multilingualism and international tourism: a content-and discourse-based approach to language-related judgments in web 2.0 hotel reviews. Language and Intercultural Communication, 16(2), 235-253.

Grönroos, C. (1984). A service quality model and its marketing implications. European Journal of marketing, 18(4), 36-44.

Grönroos, C. (1978). A Service-Oriented Approach to Marketing of Services. European Journal of Marketing, 12(8), 588-601.

Gopinath, M. \& Glassman, M. (2008). The Effect of Multiple Language Product Descriptions on Product Evaluations. Psychology \& Marketing, 25 (3), 233-261.

Hale, S. A. (2016). User Reviews and Language: How Language Influences Ratings. In Proceedings of the 2016 CHI Conference Extended Abstracts on Human Factors in Computing Systems,1208-1214.

Hall, E. T. (1984), The Dance of Life. Garden City, NY: Doubleday.

Harrison-Walker, L. J. (2001). The measurement of word-of-mouth communication and an investigation of service quality and customer commitment as potential antecedents. Journal of Service Research, 4(1), 60-75.

Hennig-Thurau, T. (2004). Customer orientation of service employees: Its impact on customer satisfaction, commitment, and retention. International Journal of Service Industry Management, 15(5), 460-478.

Hennig-Thurau, T., Gwinner, K.P., Walsh, W., \& Gremler, D.D. (2004). Electronic word-of-mouth via Consumer-opinion platforms: What motivates consumers to Articulate themselves on the Internet? Journal of Interactive Marketing, 18(1), 38-52.

Hofstede, G. (1980). Culture's Consequences: International Differences in Work-Related Values, Beverly Hills, CA: Sage Publications.

Holmqvist, J., Van Vaerenbergh, Y., Grönroos, C. (2017). Language use in services: Recent advances and directions for future research. Journal of Business Research, 72, 114-118

Holmqvist, J., \& Grönroos, C. (2012). How does language matter for services? Challenges and propositions for service research. Journal of Service Research, 15(4), 430-442.

Kandampully, J., Mok, C., \& Sparks, B. (2001). Service quality management in hospitality, tourism, and lei- sure. Binghamton, NY: The Haworth Hospitality Press.

Kenesei, Z., \& Stier, Z. (2017). Managing communication and cultural barriers in intercultural service encounters: Strategies from both sides of the counter. Journal of Vacation Marketing, 23(4), 307-321.

Kulik, C. T., \& Robert Jr, L. (2000). Demographics in service encounters: Effects of racial and gender congruence on perceived fairness. Social Justice Research, 13(4), 375-402.

Lenihan, A. (2011). Join our community of translators: Language ideologies and Facebook. Digital discourse: Language in the new media, 48-64.

Li, J., Xu, L., Tang, L., Wang, S., \& Li, L. (2018). Big data in tourism research: A literature review. Tourism Management. 68, 301-323. 
Litvin, S.W., Goldsmith, R.E., \& Pan, B. (2008). Electronic word-of-mouth in hospitality and tourism management. Tourism Management, 29, 458-468.

Liu, Y., Teichert, T., Rossi, M., Li, H., \& Hu, F. (2017). Big data for big insights: Investigating language-specific drivers of hotel satisfcation with 412,784 user-genertaed reviews. Tourism Management. 59, 554-563.

Liu, Z., \& Park, S. (2015). What Makes a Useful Online Review? Implication for Travel Product Websites. Tourism Management, 47, 140-151Lovelock, C. H. (1983). Classifying services to gain strategic marketing insights. The Journal of Marketing, 9-20.

Luna, D., \& Peracchio, L. A. (2002). Where there is a will...: Motivation as a moderator of language processing by bilingual consumers. Psychology \& Marketing, 19(7-8), 573-593.

Ma, X., Khansa, L., Deng, Y. \& Kim, S.S (2013). Impact of Prior Reviews on the Subsequent Review Process in Reputation Systems, Journal of Management Information Systems, 30 (3), 279-310.

Manzur, L., \& Jogaratnam, G. (2007). Impression management and the hospitality service encounter: cross-cultural differences. Journal of Travel \& Tourism Marketing, 20(3-4), 2132.

Mariani, M. M. \& Borghi, M. (2018). Effects of the booking.com rating system: bringing hotel class into the picture. Tourism Management, 66, 47-52.

Mariani, M.M., Baggio, R., (2012). Special issue: managing tourism in a changing world: issues and cases. Anatolia: An International Journal of Tourism and Hospitality Research, 23 (1), $1-3$.

Mariani, M.M., Borghi, M., Gretzel, U. (2019). Online reviews: differences by submission device. Tourism Management, 70, 295-298.

Mariani, M.M., Buhalis, D., Longhi, C., Vitouladiti, O. (2014a). Managing change in tourism destinations: key issues and current trends. Journal of Destination Marketing and Management, 2, 269-272.

Mariani, M.M., Baggio, R., Buhalis, D., Longhi, C. (2014b). Tourism Management, Marketing and Development: the Importance of Networks and ICTs. Palgrave, New York.

Mariani, M.M., Baggio, R., Buhalis, D., Longhi, C. (2014c). Introduction. In: Mariani, M.M., Baggio, R., Buhalis, D., Longhi, C. (Eds.), Tourism Management, Marketing, and Development. Palgrave Macmillan, New York.

Mariani, M., Baggio, R., Fuchs, M., Höepken, W. (2018a). Business intelligence and big data in hospitality and tourism: a systematic literature review. International Journal of Contemporary Hospitality Management, 30(12), 3514-3554.

Mariani, M., Di Fatta, G., Di Felice, M., 2018, 2018b. Understanding customer satisfaction with services by leveraging Big Data: the role of services attributes and consumers' cultural background. IEEE Access, forthcoming.

Mattila, A. S. (2001). The impact of relationship type on customer loyalty in a context of service failures. Journal of Service Research, 4(2), 91-101.

Mattila, A. S. (2000). The impact of culture and gender on customer evaluations of service encounters. Journal of Hospitality \& Tourism Research, 24(2), 263-273.

Mattila, A. S. (1999). The role of culture and purchase motivation in service encounter evaluations. Journal of Services Marketing, 13(4/5), 376-389.

McCleary, K.W., Choi, B.M., \& Weaver, P. (1998). A comparison of hotel selection criteria between US and Korean business travelers. Journal of Hospitality and Tourism Research, $22(1), 25-38$.

Mok, C., \& Armstrong, R. W. (1998). Expectations for hotel service quality: Do they differ from culture to culture?. Journal of Vacation Marketing, 4(4), 381-391.

Pacheco L. (2016) An analysis of online reviews by language groups: the case of hotels in Porto, Portugal. European Journal of Tourism Research, 14, 66-74. 
Parasuraman, A., Ziethaml, V., \& Berry, L.L. (1988). SERVQUAL: A Multiple- Item Scale for Measuring Consumer Perceptions of Service Quality, Journal of Retailing, 62(1), 12-40.

Pizam, A., \& Ellis, T. (1999). Customer satisfaction and its measurement in hospitality enterprises. International Journal of contemporary hospitality management, 11(7), 326339.

Puntoni, S., De Langhe, B., \& Van Osselaer, S. M. (2008). Bilingualism and the emotional intensity of advertising language. Journal of Consumer Research, 35(6), 1012-1025.

Rafaeli, A., \& Sutton, R. I. (1987). Expression of emotion as part of the work role. Academy of management review, 12(1), 23-37.

Reichheld, F.F. (2003). The one number you need to grow. Harvard business review, 81(12), 46-55.

Reisinger, Y., \& Turner, L. (1999). A cultural analysis of Japanese tourists: challenges for tourism marketers. European Journal of Marketing, 33(11/12), 1203-1227.

Russell, J. A., Weiss, A., \& Mendelsohn, G. A. (1989). Affect grid: a single-item scale of pleasure and arousal. Journal of Personality and Social Psychology, 57(3), 493.

Sainaghi, R., Phillips, P., \& Corti, V. (2013). Measuring hotel performance: Using a balanced scorecard perspectives' approach. International Journal of Hospitality Management, 34, 150-159.

Schuckert, M., Liu, X., \& Law, R. (2015). A segmentation of online reviews by language groups: How English and non-English speakers rate hotels differently. International Journal of Hospitality Management, 48, 143-149

Shaw, G., Bailey, A., \& Williams, A. (2011). Aspects of service-dominant logic and its implications for tourism management: Examples from the hotel industry. Tourism Management, 32(2), 207-214.

Shoemaker, S., \& Lewis, R. C. (1999). Customer loyalty: the future of hospitality marketing. International journal of hospitality management, 18(4), 345-370.

Shostack, L. (1985). Planning the service encounter. The service encounter, 243-254.

Shostack, G.L. (1984). Designing services that deliver. Harvard Business Review, 62, 133-139.

Shostack, G. L. (1977). Breaking Free from Product Marketing, Journal of Marketing, 41(2), 73-80.

Sizoo, S., Iskat, W., Plank, R., \& Serrie, H. (2004). Cross-cultural service encounters in the hospitality industry and the effect of intercultural sensitivity on employee performance. International journal of hospitality \& tourism administration, 4(2), 61-77.

Smakman, D. (2015). The Westernising mechanisms in sociolinguistics. Globalizing Sociolinguistics: Challenging and Expanding Theory. London: Routledge, 16-35.

Solomon, M. R., Surprenant, C., Czepiel, J. A., \& Gutman, E. G. (1985). A role theory perspective on dyadic interactions: the service encounter. The Journal of Marketing, 49 (1), 99-111.

Sparks, B., \& Callan, V. J. (1992). Communication and the service encounter: The value of convergence. International Journal of Hospitality Management, 11(3), 213-224.

Sparks, B. (1994). Communicative aspects of the service encounter. Journal of Hospitality and Tourism Research, 17(2), 39-50.

Sparks, B. A., \& McColl-Kennedy, J. R. (2001). Justice strategy options for increased customer satisfaction in a services recovery setting. Journal of Business Research, 54(3), 209-218.

Sun, H. (2001). Building a Culturally-Competent Corporate Website: An Exploratory Study of Cultural Markers in Multilingual Web Design. Proceedings of the 19th Annual International Conference on Computer Documentation (ACM), Sante Fe, 95-102.

UNWTO (2017). UNWTO Tourism Highlights. 2017 Edition. https://www.eunwto.org/doi/pdf/10.18111/9789284419029 (accessed March.06.2018).

UNWTO (2018), "2017 International Tourism Results: the highest in seven years" Press Release No.: 18003, 15 Jan 18. http://media.unwto.org/press-release/2018-01-15/2017international-tourism-results-highest-seven-years (accessed 23/03/2018). 
Vargo, S. L., \& Lusch, R. F. (2004). Evolving to a new dominant logic for marketing. Journal of Marketing, 68(1), 1-17.

Vásquez, C. (2014). The discourse of online consumer reviews. London: Bloomsbury Publishing.

Wang, Y., Royo Vela, M., \& Tyler, K. (2008). Cultural perspectives: Chinese perceptions of UK hotel service quality. International Journal of Culture, Tourism and Hospitality Research, 2(4), 312-329.

Wang, C. Y., Miao, L., \& Mattila, A. S. (2015). Customer responses to intercultural communication accommodation strategies in hospitality service encounters. International Journal of Hospitality Management, 51, 96-104.

Winsted, K. F. (1997). The service experience in two cultures: A behavioral perspective. Journal of Retailing, 73(3), 337-360.

WTTC (2018), 2018 World Economic Impact for the travel and tourism industry. London.

Wu, L., Shen, H., Fan, A., \& Mattila, A. S. (2017). The impact of language style on consumers' reactions to online reviews. Tourism Management, 59, 590-596.

Xiang, Z., Du, Q., Ma, Y., \& Fan, W. (2017). A comparative analysis of major online review platforms: Implications for social media analytics in hospitality and tourism. Tourism Management, 58, 51-65.

Yung, E., \& Chan, A. (2002). Business traveler satisfaction with hotel service encounters. Journal of Travel \& Tourism Marketing, 11(4), 29-41.

Zeithaml, V., Parasuraman, A., \& Berry, L.L. (1990). Delivering Quality Service: Balancing Customer Perceptions and Expectations. New York: The Free Press.

Zeithaml, V.A., Bitner, M.J., \& Gremler, D.D. (2006), Services Marketing: Integrating Customer Focus Across the Firm, McGraw-Hill Companies, Boston, MA.Zeithaml, V. A., Berry, L. L., \& Parasuraman, A. (1996). The behavioral consequences of service quality. Journal of Marketing, 60 (2), 31-46. 